\title{
Pasireotide, a multiple somatostatin receptor subtypes ligand, reduces cell viability in non-functioning pituitary adenomas by inhibiting vascular endothelial growth factor secretion
}

\author{
Maria Chiara Zatelli, Daniela Piccin, Cristina Vignali, Federico Tagliati, Maria \\ Rosaria Ambrosio, Marta Bondanelli, Vincenzo Cimino ${ }^{1}$, Antonio Bianchi ${ }^{1}$, \\ Herbert A Schmid ${ }^{2}$, Massimo Scanarini ${ }^{3}$, Alfredo Pontecorvi ${ }^{1}$, Laura De Marinis ${ }^{1}$, \\ Giulio Maira ${ }^{4}$ and Ettore $C$ degli Uberti
}

\author{
Section of Endocrinology, Department of Biomedical Sciences and Advanced Therapies, University of Ferrara, Via Savonarola 9 \\ 44100 Ferrara, Italy ${ }^{1}$ Institute of Endocrinology, Catholic University of Rome, 00168 Rome, Italy \\ ${ }^{2}$ Novartis Institutes for Biomedical Research, Oncology, 4002 Basel, Switzerland \\ ${ }^{3}$ Division of Neurosurgery - Hospital of Padova, 35100 Padova, Italy \\ ${ }^{4}$ Department of Neurosurgery, Catholic University of Rome, 00168 Rome, Italy
}

(Requests for offprints should be addressed to E C degli Uberti; Email: dut@unife.it)

\begin{abstract}
Somatostatin (SRIF) analogs have been employed in medical therapy of non-functioning pituitary adenomas (NFA), with contrasting results. Previous evidence showed that SRIF can exert its antiproliferative effects by reducing vascular endothelial growth factor (VEGF) secretion and action, and that VEGF expression may be related to pituitary tumor growth. The aim of our study was to clarify the possible effects of a multireceptor SRIF ligand on VEGF secretion and cell proliferation in human NFA primary cultures. We assessed the expression of SRIF receptors (SSTR1-5), the in vitro effects on VEGF secretion, and on cell viability of SRIF and of the stable SRIF analog pasireotide (SOM230), which activates SSTR1, 2, 3, and 5. Twenty-five NFA were examined by RT-PCR for expression of $\alpha$-subunit, SSTR, VEGF, and VEGF receptors 1 (VEGFR1) and 2 (VEGF-R2). Primary cultures were tested with SRIF and with pasireotide. All NFA samples expressed $\alpha$-sub, VEGF and VEGFR-1 and 2, while SSTR expression pattern was highly variable. Two different groups were identified according to VEGF secretion inhibition by SRIF. VEGF secretion and cell viability were reduced by SRIF and pasireotide in the 'responder' group, but not in the 'non-responder' group, including NFA expressing SSTR5. SRIF and pasireotide completely blocked forskolin-induced VEGF secretion. In addition, SRIF and pasireotide completely abrogated the promoting effects of VEGF on NFA cell viability. Our data demonstrate that pasireotide can inhibit NFA cell viability by inhibiting VEGF secretion, and suggest that the multireceptor-SSTR agonist pasireotide might be useful in medical therapy of selected NFA.
\end{abstract}

Endocrine-Related Cancer (2007) 14 91-102

\section{Introduction}

Increased expression of vascular endothelial growth factor (VEGF), a specific mitogen for endothelial cell, has been demonstrated in several human neoplastic tissues (Ferrara 2001), which is associated with blood vessel density, tumor growth, metastatic spread, disease progression, and poor prognosis (Itakura et al. 1997, Seo et al. 2000). Several studies have shown that VEGF is expressed in the pituitary gland and pituitary adenomas, where VEGF expression correlates with increased proliferation (Vidal et al. 2000, Yamada \& Takada 2003). Moreover, elevated plasma VEGF levels have been demonstrated in 
patients harboring pituitary tumors (Komorowski et al. 2000). In addition, increased concentrations of VEGF and of VEGF receptor 1 (VEGF-R1) were found in non-functioning pituitary adenomas (NFA) when compared with normal pituitaries (McCabe et al. 2002), suggesting that VEGF and VEGF-R1 expression may be related to pituitary tumor growth and vascularization.

Previous evidence has shown that somatostatin (SRIF) and its analogs might exert antiproliferative effects on pituitary adenomas, by interacting with one or more of its five transmembrane G-protein-coupled receptors (SSTR1-5; Zatelli et al. 2006b). In addition, overexpression of SSTR2 in human pancreatic cancer cells markedly reduced microvessel density and VEGF expression (Carrere et al. 2005), suggesting that SSTR2-induced antiproliferative effects might be mediated by a reduction in VEGF secretion and action in a paracrine fashion. Recently, a new universal SRIF analog with binding properties similar to native SRIF has been developed. The new compound, pasireotide, previously known as SOM230, has high affinity for and functional activity at SSTR1, 2, 3, and 5 (Bruns et al. 2002, Schmid \& Schoeffter 2004). Pasireotide has been demonstrated to act as a powerful inhibitor of growth hormone $(\mathrm{GH})$ secretion by normal somatotrophs in animal models (Weckbecker et al. 2002) and by somatotroph adenomas, both in vivo and in vitro (Hofland et al. 2005). A recent study demonstrates that treatment with both octreotide and pasireotide are associated with the downregulation of pERK and upregulation of p27 in pituitary adenomas, possibly hampering cell cycle progression and inhibiting cell growth (Hubina et al. 2006). Moreover, pasireotide has been reported to inhibit VEGF-stimulated endothelial cell proliferation (Adams et al. 2004). However, the mechanism by which such effect might take place in human NFA has never been investigated, so far.

We therefore investigated the effects of SRIF and of pasireotide on VEGF secretion and on cell viability in vitro in a group of 25 NFA.

\section{Materials and methods}

\section{Materials}

All reagents, if not otherwise specified, were purchased from Sigma-Aldrich (Milano, Italy).

\section{Human pituitary adenomas}

Twenty-five clinically NFA (mean maximal diameter: $1.9 \pm 0.1 \mathrm{~cm}$; mean volume: $3.8 \pm 1.9 \mathrm{~cm}^{3}$ ) from 25 patients, aged $54.7 \pm 3.5$ years (median 53 years), 10 males and 15 females, operated on for NFA were recruited for this study. Table 1 shows patients' characteristics and preoperative hormonal values. Patients had not been treated with SRIF analogs or with dopaminergic drugs prior to surgery. All patients underwent transsphenoidal surgery, and all specimens were examined for anterior pituitary hormones by immunohistochemistry. Among the 25 tumors, 3 were positive for follicle-stimulating hormone (FSH), 1 for lutenizing hormone (LH), 2 for prolactin (PRL), and 2 for both LH and FSH. No immunostaining for $\mathrm{GH}$, $\mathrm{TSH}$, and ACTH was detectable in these tumors and all anterior pituitary hormones were undetectable in the other 17 tumors. Therefore, these adenomas were histologically diagnosed as gonadotroph cell adenoma or null cell adenoma. Human total RNA from normal pituitary was used as a control for RT-PCRs (Analytical Biological Services Inc., Wilmington, Delaware, USA).

\section{Tissue collection and primary culture}

Tissue samples were collected in accordance with the guidelines of the local committee on human research. A fragment was immediately frozen in liquid nitrogen under ribonuclease (RNase)-free conditions at the time of surgery and stored at $-80{ }^{\circ} \mathrm{C}$ until RNA isolation was performed. A portion of the fresh tissue was immediately processed for primary culture experiments as described previously (Zatelli et al. 2003a). Cells were resuspended in high glucose DMEM with 10\% FBS and antibiotics (EuroClone Ltd), seeded in 96-well culture plates $(\sim 2 \times$ $10^{4}$ cells/well; $\sim 80$-well/tumor) and incubated at $37^{\circ} \mathrm{C}$ in a humidified atmosphere of $5 \% \mathrm{CO}_{2}$ and $95 \%$ air. Fibroblast contamination was excluded by treatment with cis-4-hydroxy-L-proline and morphological examination of the cultured cells (Danila et al. 2001). After $24 \mathrm{~h}$, the medium was changed to serum-free high glucose DMEM containing $0.2 \%$ BSA, $120 \mathrm{nM}$ transferrin, $5 \mathrm{U} / \mathrm{l}$ insulin, $2 \mathrm{mM}$ glutamine, and antibiotics. Cells were then treated with the indicated compounds for evaluation of VEGF secretion in conditioned medium, which was collected and stored at $-20{ }^{\circ} \mathrm{C}$ for later measurement. Medium was then replaced with the indicated treatments for cell viability experiments. Informed consent of the patients was obtained for disclosing clinical investigation and performing the in vitro study.

\section{Isolation of RNA and RT-PCR}

In order to demonstrate the pituitary origin of the samples, RT-PCR analysis for $\boldsymbol{\alpha}$-subunit expression 
Table 1 Patients' characteristics, preoperative hormonal values and in vitro VEGF secretion by NFA

\begin{tabular}{|c|c|c|c|c|c|c|c|c|c|c|c|c|c|c|c|}
\hline Patient no. & Sex & Age & $\begin{array}{c}\text { LH } \\
(\mathrm{mlU} / \mathrm{ml})\end{array}$ & $\begin{array}{c}\text { FSH } \\
(\mathrm{mlU} / \mathrm{ml})\end{array}$ & $\begin{array}{c}\text { PRL } \\
\text { (ng/ml) }\end{array}$ & $\begin{array}{c}\alpha \text {-sub- } \\
\text { unit } \\
\text { (mlU/ml) }\end{array}$ & $\mathbf{G H}(\mu \mathrm{g} / \mathrm{l})$ & $\begin{array}{l}\text { IGF-1 } \\
(\mu \mathrm{g} / \mathrm{l})\end{array}$ & $\begin{array}{c}\text { ACTH } \\
(\mathrm{ng} / \mathrm{l})\end{array}$ & $\begin{array}{c}\text { Cortisol } \\
(\mu \mathrm{mol} / \mathrm{l})\end{array}$ & $\begin{array}{c}\text { TSH } \\
(\mu \mathrm{IU} / \mathrm{ml})\end{array}$ & $\begin{array}{c}\text { FT4 } \\
(\mathrm{pmol} / \mathrm{l})\end{array}$ & $\mathbf{T}(\mathrm{nmol} / \mathrm{l})$ & $\begin{array}{c}\text { E2 } \\
(\mathrm{pmol} / \mathrm{l})\end{array}$ & $\begin{array}{c}\text { In vitro } \\
\text { VEGF }\end{array}$ \\
\hline 1 & $M$ & 47 & 1.67 & 9.00 & 21.00 & 0.20 & $<0.01$ & 84.0 & 23.2 & 0.27 & 2.91 & 10.20 & 8.90 & - & 16.7 \\
\hline 2 & $\mathrm{~F}$ & 53 & 1.60 & 2.90 & 30.40 & 0.10 & 0.20 & 193.0 & 40.2 & 0.28 & 0.85 & 12.00 & - & 7.70 & 44.3 \\
\hline 3 & $M$ & 73 & 0.50 & 4.80 & 15.50 & 2.05 & $<0.01$ & 52.6 & 15.2 & 0.25 & 2.81 & 9.68 & 7.70 & - & 57.8 \\
\hline 4 & $M$ & 75 & 0.50 & 4.80 & 15.50 & 0.05 & $<0.01$ & 52.0 & 15.2 & 0.15 & 2.81 & 9.68 & 7.70 & - & 11.3 \\
\hline 5 & $\mathrm{M}$ & 43 & 2.80 & 1.10 & 26.10 & 0.02 & 0.01 & 95.0 & 12.0 & 0.24 & 0.99 & 12.80 & 4.10 & - & 19.7 \\
\hline 6 & $\mathrm{~F}$ & 40 & 1.58 & 4.50 & 89.40 & 0.03 & 0.15 & 109.0 & 28.0 & 0.20 & 1.24 & 14.60 & - & 4.30 & 15.4 \\
\hline 7 & $\mathrm{~F}$ & 71 & 2.30 & 11.40 & 11.70 & 0.01 & 0.08 & 66.6 & 9.9 & 0.76 & 0.46 & 14.32 & - & 8.20 & 12.6 \\
\hline 8 & $\mathrm{~F}$ & 76 & 1.10 & 3.30 & 69.80 & 1.05 & 0.06 & 87.0 & 22.9 & 0.27 & $<0.01$ & 15.40 & - & 6.80 & 23.7 \\
\hline 9 & $\mathrm{~F}$ & 35 & 0.10 & 3.90 & 104.60 & 0.05 & 0.27 & 150.0 & 13.0 & 0.22 & 4.23 & 9.30 & - & 9.40 & 10.2 \\
\hline 10 & $\mathrm{~F}$ & 76 & 0.30 & 1.70 & 28.50 & 0.75 & 0.12 & 108.0 & 21.4 & 0.35 & 0.50 & 16.90 & - & 13.40 & 31.5 \\
\hline 11 & $M$ & 76 & 1.30 & 3.40 & 48.90 & 0.12 & 0.09 & 17.9 & 7.2 & 0.26 & 0.80 & 9.00 & 13.30 & - & 11.7 \\
\hline 12 & $\mathrm{~F}$ & 30 & 1.58 & 4.50 & 25.80 & 0.04 & 0.30 & 155.0 & 27.4 & 0.75 & 0.46 & 11.20 & - & 13.65 & 17.2 \\
\hline 13 & $\mathrm{~F}$ & 49 & $<0.1$ & 2.20 & 16.20 & 0.85 & 0.10 & 57.0 & 22.0 & 0.36 & 2.14 & 8.77 & - & 7.40 & 24.8 \\
\hline 14 & $\mathrm{~F}$ & 74 & 2.30 & 11.40 & 11.70 & 1.25 & $<0.01$ & 52.0 & 23.5 & 0.27 & 0.96 & 11.50 & - & 8.70 & 31.7 \\
\hline 15 & $M$ & 31 & 1.80 & 12.00 & 12.50 & 0.62 & 0.05 & 148.0 & 15.2 & 0.28 & 1.57 & 12.60 & 9.30 & - & 15.3 \\
\hline 16 & $\mathrm{~F}$ & 41 & 5.50 & 17.60 & 70.20 & 0.09 & 0.10 & 228.0 & 19.8 & 0.38 & 1.47 & 15.52 & - & 73.40 & 44.7 \\
\hline 17 & $\mathrm{~F}$ & 44 & 0.70 & 5.30 & 9.20 & 0.37 & 0.28 & 329.0 & 16.7 & 0.40 & 0.44 & 10.26 & - & 6.30 & 20.6 \\
\hline 18 & $\mathrm{~F}$ & 63 & 31.40 & 83.00 & 15.70 & 0.04 & 2.41 & 140.5 & 35.2 & 0.37 & 8.48 & 15.35 & - & 54.10 & 18.9 \\
\hline 19 & $\mathrm{~F}$ & 67 & 10.20 & 77.20 & 10.70 & 0.90 & 0.01 & 90.7 & 18.7 & 0.25 & 2.18 & 14.19 & - & 55.05 & 13.8 \\
\hline 20 & $\mathrm{~F}$ & 64 & 8.30 & 28.40 & 19.40 & 0.16 & 0.02 & 104.4 & 16.9 & 0.37 & 0.86 & 18.45 & - & 66.06 & 19.4 \\
\hline 21 & $M$ & 58 & 0.70 & 5.60 & 7.70 & 0.57 & 0.20 & 62.1 & 12.7 & 0.29 & 5.74 & 10.32 & 20.65 & - & 9.8 \\
\hline 22 & $M$ & 29 & 1.70 & 13.50 & 24.90 & 0.04 & 0.18 & 142.0 & 23.9 & 0.43 & 0.99 & 14.10 & 10.50 & - & 33.2 \\
\hline 23 & $\mathrm{M}$ & 43 & 1.80 & 2.50 & 8.20 & 0.63 & 0.05 & 137.0 & 38.2 & 0.38 & 2.60 & 14.84 & 13.86 & - & 47.4 \\
\hline 24 & $M$ & 74 & 1.90 & 2.50 & 13.30 & 1.23 & 0.28 & 51.5 & 17.1 & 0.30 & 0.49 & 10.84 & 13.30 & - & 12.7 \\
\hline 25 & $\mathrm{~F}$ & 35 & 3.20 & 14.70 & 11.30 & 1.47 & 0.05 & 123.0 & 45.9 & 0.33 & 1.59 & 17.67 & - & 37.10 & 16.8 \\
\hline
\end{tabular}

T, testosterone (shown only in male subjects); E2, $17 \beta$-estradiol (shown only in female subjects).

aLevels of VEGF $(\mathrm{pg} / \mathrm{ml})$ in control culture medium from $12 \times 10^{4}$ cells cultured for $12 \mathrm{~h}$. 
was performed on each specimen, as reported previously (Zatelli et al. 2004). Further expression analysis for VEGF, VEGF-R1, VEGF-R2, and SSTR1SSTR5 was performed only in $\alpha$-subunit-expressing tissues, as previously described (Zatelli et al. 2003b, 2004). Briefly, frozen tissues were disrupted and total RNA from the pulverized tumors was isolated with TRIzol reagent (Invitrogen), according to the manufacturer's protocol. To prevent DNA contamination, RNA was treated with RNase-free DNase (Promega). Using a first strand cDNA synthesis kit (SuperScript Preamplification System for First Strand cDNA Synthesis, Invitrogen), $1 \mu \mathrm{g}$ total RNA was reversetranscribed with random hexamers according to the manufacturer's protocol. Reverse transcription (RT) reactions were performed by using the GeneAmp 9700 PCR System (Applera, Monza, Italy), as described previously (Zatelli et al. 2001, 2003a). PCR conditions and oligonucleotide primers for amplification are listed in Table 2. Glyceraldehyde phosphate dehydrogenase (GAPDH) amplification was performed as control for RT reaction. PCR products were run on a $2 \%$ agarose gel, visualized by ethidium bromide staining, and analyzed with the Fluor-S Multi Imager (Bio-Rad). To confirm the correct identification of RT-PCR products, their specificity was verified, after gel purification by Quiaex II (Qiagen), by restriction enzyme digestion and direct sequencing (data not shown).

\section{SSTR Quantitative PCR}

Quantitative PCR (QPCR) for SSTR1, SSTR2, SSTR3, SSTR4, and SSTR5 was performed as previously described (Zatelli et al. 2006a), with primers and probes designed using Primer Express Software (Applied Biosystems, Monza, Italy). TaqMan probes (PE Applied Biosystems) labeled with a fluorescent dye (6-carboxy-fluorescein, FAM) and a quencher dye (6-carboxy-tetramethyl rhodamine, TAMRA) were used. For amplification of the house keeping gene the Pre-Developed TaqMan Assay Reagents for the Human 18S rRNA $(20 \times)$ were used (PE Applied Biosystem).

Serial dilutions of the single stranded SSTR1, SSTR2, SSTR3, SSTR4, and SSTR5 sense oligonucleotide amplicons (from $10^{9}$ to $10^{2}$ molecules) were carried out in triplicate. The log copy numbers of unknown samples were calculated from the regression line according to the equation: $\log N=(\mathrm{Ct}-q) / m$, where $\mathrm{Ct}$ is the threshold cycle, $q$ is the $y$-intercept, and $m$ is the slope of the standard curve line. All QPCRs were performed, recorded, and analyzed using the ABI 7700 Prism Sequence Detection System

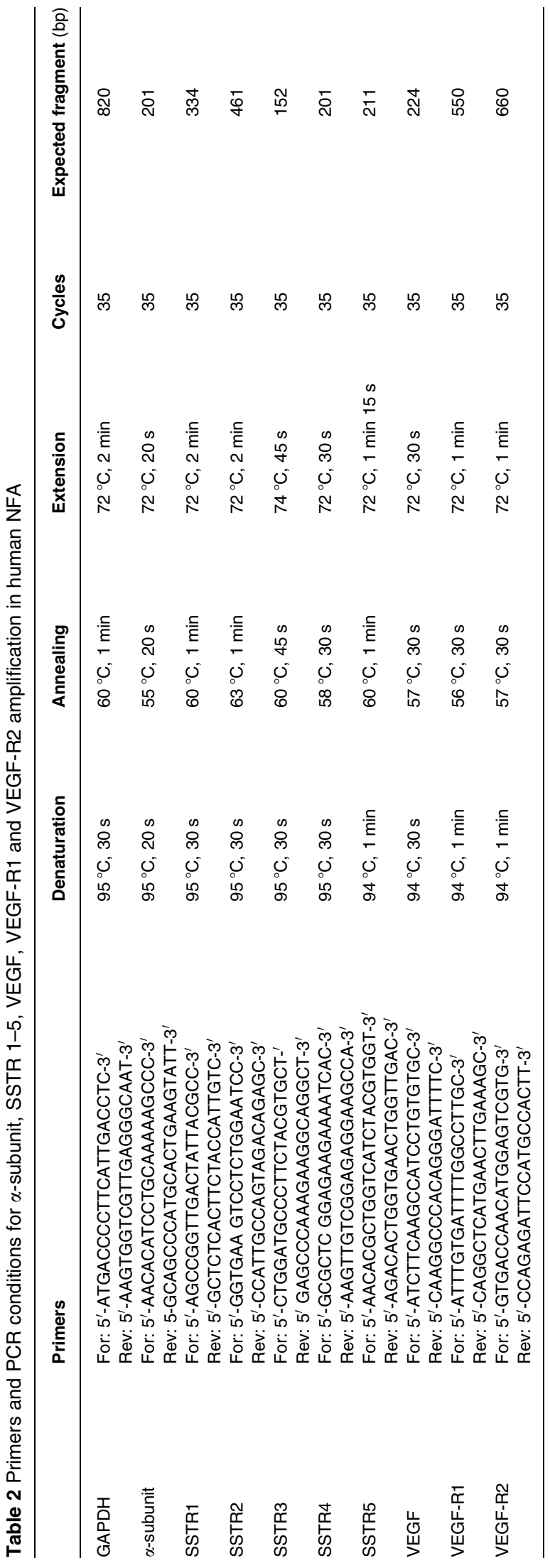


(PE Applied Biosystems). Slopes for all assays reported were $-3.3 \pm 0.1$.

All samples were carried out in triplicate (100 ng reverse-transcribed total RNA per well) and repeated at least twice. For each samples, one point of $18 \mathrm{~S}$ rRNA was loaded to evaluate the retro-transcription efficiency in the same plate and PCR conditions. No Template Control and RT- controls were run in each experiment.

A cut-off of $3 \times 10^{3}$ mRNA copies/ $\mu \mathrm{g}$ total RNA was established as the threshold for Real Time PCR to exclude the detection of transcripts due to illegitimate transcription, as suggested previously (Chelly et al. 1989, Korbonits et al. 2001).

\section{SRIF and pasireotide}

SRIF (Stilamin 250) was purchased from Serono Pharma (Roma, Italy). Functional responses were also investigated by using pasireotide (provided by Novartis Pharma, Basel, Switzerland), which affinities to the different SSTRs are listed in Table 3, according to previously published evidence (Bruns et al. 2002).

\section{VEGF secretion}

The effects of SRIF and pasireotide on VEGF secretion were analyzed by measuring human VEGF immunoreactivity with an ELISA kit (Pierce Biotechnology, Inc., Rockford, IL, USA) in the culture medium from primary cultured pituitary cells incubated for $8 \mathrm{~h}$ with or without $10^{-8} \mathrm{M}$ SRIF or pasireotide. The detection limit was $8 \mathrm{pg} / \mathrm{ml}$, with intra- and inter-assay coefficients of variation of 8.9 and $7.3 \%$ respectively. Hormone assays were performed in duplicate after appropriate sample dilutions of conditioned medium from treated cells. Results were obtained by determining the mean value among eight replicates. Primary cultures were considered as 'responders' when a significant reduction $>15 \%$ in VEGF secretion was recorded under treatment with SRIF.

\section{Cell viability}

The effect of SRIF and pasireotide on cell viability of pituitary adenomas in vitro was assessed by the CellTiter 96 Aqueous Non-Radioactive Cell

Table 3 Human somatostatin receptor subtype specificity (IC50-nM) SSTR subtype

\begin{tabular}{lclccc}
\hline Compound & $\mathbf{1}$ & $\mathbf{2}$ & $\mathbf{3}$ & $\mathbf{4}$ & $\mathbf{5}$ \\
\hline SRIF & 1.95 & 0.25 & 1.2 & 1.77 & 1.41 \\
SOM230 & 9.3 & 1.0 & 1.5 & $>1000$ & 0.16 \\
\hline
\end{tabular}

Proliferation Assay (Promega), as described previously (Zatelli et al. 2002), after incubation for $48 \mathrm{~h}$ in medium without or with $10^{-8}$ M SRIF or pasireotide. 3-(4,5-dimethylthiazol-2-yl)-2,5-diphenyltetrazolium bromide (MTT) is a colorimetric method for determining the number of viable cells, widely accepted and employed for cell viability assessment (Zatelli et al. $2003 a$ ), as the recorded absorbance strongly correlates to the cell number, independently on whether they are proliferating or not. Treatments were renewed after the first $24 \mathrm{~h}$ of incubation. At the end of the incubation period, the plates were incubated for an additional $4 \mathrm{~h}$ at $37{ }^{\circ} \mathrm{C}$ in a humidified $5 \% \mathrm{CO}_{2}$ atmosphere with the staining solution. The absorbance at $490 \mathrm{~nm}$ was then recorded using an ELISA plate reader (EASIA Reader, Medgenix, Fleurus, Belgium). Results (absorbance at $490 \mathrm{~nm}$ ) were obtained by determining the mean value of at least six experiments in eight replicates.

\section{Statistical analysis}

Results of hormone assays and cell viability experiments are expressed as the mean \pm s.E.M. A preliminary analysis was carried out to determine whether the datasets conformed to a normal distribution, and a computation of homogeneity of variance was performed using Bartlett's test. The results were compared within each group and between groups using ANOVA. If the $F$ values were significant $(P<0.05)$, Student's paired or unpaired $t$-test was used to evaluate individual differences between means.

\section{Results}

\section{Somatostatin receptor mRNA expression}

Twenty-five samples derived from patients operated on for NFA underwent RT-PCR analysis for $\alpha$-sub. All samples expressed $\alpha$-sub and therefore underwent evaluation of SSTR1-5, VEGF, VEGF-R1, and VEGFR2 mRNA expression. All samples expressed VEGF and at least one VEGF receptor subtype (VEGF-R1 in 22, and VEGF-R2 in 23 samples). SSTR expression pattern was highly variable, as SSTR1 was expressed in $68 \%$ of the samples, SSTR2 in 88\%, SSTR3 in 68\%, SSTR4 in 64\%, and SSTR5 in 36\% (Table 4).

The absolute SSTRs mRNA levels were also investigated in the selected samples showing a mean \pm s.E.M. molecules $/ \mu \mathrm{g}$ reverse-transcribed total RNA for SSTR1 mRNA of $3.1 \pm 0.1 \times 10^{5}$, for SSTR2 mRNA of $1.1 \pm 0.3 \times 10^{9}$, for SSTR3 mRNA of $8.0 \pm$ $0.1 \times 10^{4}$, for SSTR 4 mRNA of $5.5 \pm 0.4 \times 10^{3}$, and for SSTR5 mRNA of $6.6 \pm 0.2 \times 10^{6}$ (Table 5). No correlation was found between SSTR expression 
Table 4 SSTR1-5, VEGF, VEGF-R1, and VEGF-R2 expression in 25 human NFA

\begin{tabular}{|c|c|c|c|c|c|c|c|c|}
\hline No. & SSTR1 & SSTR2 & SSTR3 & SSTR4 & SSTR5 & VEGF-R1 & VEGF-R2 & VEGF \\
\hline 1 & - & + & - & + & - & + & - & + \\
\hline $2^{a}$ & + & - & + & - & - & + & + & + \\
\hline $3^{a}$ & + & + & - & - & - & + & + & + \\
\hline $4^{a}$ & - & + & + & - & - & + & + & + \\
\hline $5^{a}$ & + & + & - & + & - & + & + & + \\
\hline $6^{a}$ & + & - & - & + & - & + & + & + \\
\hline 7 & - & + & + & + & + & + & + & + \\
\hline 8 & + & + & - & - & + & + & + & + \\
\hline 9 & + & + & + & + & + & + & + & + \\
\hline 10 & - & + & + & + & + & + & + & + \\
\hline 11 & + & + & + & + & + & + & + & + \\
\hline 12 & + & + & + & + & + & + & - & + \\
\hline $13^{a}$ & + & + & + & - & - & - & + & + \\
\hline $14^{a}$ & + & + & + & + & - & + & + & + \\
\hline $15^{a}$ & + & + & + & + & - & + & + & + \\
\hline $16^{a}$ & + & + & + & + & - & + & + & + \\
\hline 17 & + & + & + & - & + & + & + & + \\
\hline $18^{a}$ & + & + & + & + & - & + & + & + \\
\hline 19 & + & + & + & + & + & + & - & + \\
\hline $20^{a}$ & + & + & - & + & - & - & + & + \\
\hline 21 & - & + & - & + & - & + & + & + \\
\hline 22 & - & + & + & - & + & + & + & + \\
\hline $23^{a}$ & - & + & + & - & - & + & + & + \\
\hline $24^{a}$ & - & + & + & - & - & + & + & + \\
\hline 25 & + & - & - & + & - & + & + & + \\
\hline
\end{tabular}

${ }^{a}$ Responder NFA.

pattern, patients' clinical characteristics and preoperative hormonal values.

\section{Effects of SRIF and pasireotide on VEGF secretion by NFA}

In order to determine the effects of SRIF and of pasireotide on VEGF secretion by dispersed NFA cells, we assessed VEGF concentrations in conditioned medium from 25 NFA primary cultures, treated with SRIF or pasireotide. The basal VEGF level in the culture medium of $12 \times 10^{4}$ cells cultured for $12 \mathrm{~h}$ was $23.2 \pm 2.7 \mathrm{pg} / \mathrm{ml}$. The primary cultures were then divided in two groups according to the extent of VEGF secretion inhibition recorded after treatment with SRIF. Cultures responding to SRIF with a VEGF reduction of $15 \%$ or greater versus untreated cells were considered as 'responders'. According to this criterion, 13 cultures were considered as 'responders' (group A) and 12 as 'non-responders' (group B).

SSTR1 expression was found in $77 \%$ of NFA belonging to group A, and was four-fold greater than the levels found in the SSTR1-positive NFA (58\%) belonging to group B $\left(4.5 \pm 0.2 \times 10^{5}\right.$ vs $1.1 \pm 0.2 \times$ $10^{5}$ mRNA molecules/ $\mu$ g total RNA). Expression of SSTR2 in groups A and B was found in 92 and $85 \%$ of

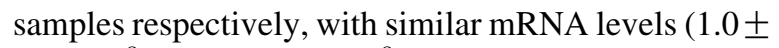
$0.3 \times 10^{9}$ vs $1.3 \pm 0.6 \times 10^{9} \mathrm{mRNA}$ molecules $/ \mu \mathrm{g}$ total RNA). On the other hand, SSTR3 was found in a similar proportion of NFA in the two groups (70 and $67 \%$ respectively), but mRNA expression levels were greater ( $\sim$ two-fold) in the 'responder' as compared with the 'non-responder' group $\left(1.0 \pm 0.1 \times 10^{5}\right.$ vs $5.7 \pm 0.6 \times 10^{4}$ mRNA molecules/ $\mu \mathrm{g}$ total RNA). Expression of SSTR4 in group A and B was found in 54 and $75 \%$ of samples respectively, with similar mRNA levels $\left(6.4 \pm 0.6 \times 10^{3}\right.$ vs $4.8 \pm 0.5 \times 10^{3}$ mRNA molecules/ $\mu$ g total RNA). On the other hand, all NFA in group A lacked expression of SSTR5, which was expressed by 9 out of 12 NFA belonging to group B $\left(6.6 \pm 0.4 \times 10^{6} \mathrm{mRNA}\right.$ molecules/ $\mu \mathrm{g}$ total RNA). All samples that were negative for SSTR expression by qualitative PCR were confirmed by quantitative PCR, since their SSTR expression levels were below the threshold to exclude the detection of transcripts due to illegitimate transcription $\left(<3 \times 10^{3}\right.$ mRNA molecules/ $\mu$ g total RNA).

In group A, VEGF secretion was reduced by $24 \%$ $(P<0.05)$ after treatment with SRIF and by $31 \%(P<$ 0.01 vs control; $P<0.05$ vs SRIF-treated cells) after treatment with the multiligand SSTR agonist pasireotide (Fig. 1). In group B, treatment with SRIF or with 
Table 5 Quantitative SSTR1-5 expression in normal pituitary and in 25 human NFA (molecules/ $\mu$ g total RNA)

\begin{tabular}{|c|c|c|c|c|c|}
\hline No. & SSTR1 & SSTR2 & SSTR3 & SSTR4 & SSTR5 \\
\hline N.P. & $3.5 \times 10^{5}$ & $1.4 \times 10^{8}$ & $1.5 \times 10^{4}$ & $<3 \times 10^{3}$ & $2.7 \times 10^{5}$ \\
\hline 1 & $<3 \times 10^{3}$ & $1.4 \times 10^{8}$ & $<3 \times 10^{3}$ & $4.5 \times 10^{3}$ & $<3 \times 10^{3}$ \\
\hline $2^{a}$ & $1.4 \times 10^{5}$ & $<3 \times 10^{3}$ & $3.6 \times 10^{4}$ & $<3 \times 10^{3}$ & $<3 \times 10^{3}$ \\
\hline $3^{a}$ & $1.5 \times 10^{4}$ & $3.2 \times 10^{8}$ & $<3 \times 10^{3}$ & $<3 \times 10^{3}$ & $<3 \times 10^{3}$ \\
\hline $4^{a}$ & $<3 \times 10^{3}$ & $3.1 \times 10^{8}$ & $1.3 \times 10^{5}$ & $<3 \times 10^{3}$ & $<3 \times 10^{3}$ \\
\hline $5^{a}$ & $4.1 \times 10^{4}$ & $2.7 \times 10^{9}$ & $<3 \times 10^{3}$ & $6.5 \times 10^{3}$ & $<3 \times 10^{3}$ \\
\hline $6^{a}$ & $1.6 \times 10^{4}$ & $<3 \times 10^{3}$ & $<3 \times 10^{3}$ & $5.5 \times 10^{3}$ & $<3 \times 10^{3}$ \\
\hline 7 & $<3 \times 10^{3}$ & $1.2 \times 10^{9}$ & $4.6 \times 10^{4}$ & $6.8 \times 10^{3}$ & $4.0 \times 10^{6}$ \\
\hline 8 & $3.9 \times 10^{4}$ & $2.7 \times 10^{9}$ & $<3 \times 10^{3}$ & $<3 \times 10^{3}$ & $5.9 \times 10^{5}$ \\
\hline 9 & $2.7 \times 10^{4}$ & $1.7 \times 10^{8}$ & $7.9 \times 10^{4}$ & $3.2 \times 10^{3}$ & $4.2 \times 10^{5}$ \\
\hline 10 & $<3 \times 10^{3}$ & $7.9 \times 10^{7}$ & $1.0 \times 10^{5}$ & $5.4 \times 10^{3}$ & $8.5 \times 10^{5}$ \\
\hline 11 & $1.3 \times 10^{5}$ & $9.5 \times 10^{7}$ & $3.9 \times 10^{3}$ & $3.8 \times 10^{3}$ & $1.1 \times 10^{7}$ \\
\hline 12 & $1.7 \times 10^{4}$ & $2.7 \times 10^{9}$ & $6.8 \times 10^{4}$ & $7.2 \times 10^{3}$ & $9.0 \times 10^{4}$ \\
\hline $13^{a}$ & $2.8 \times 10^{5}$ & $7.9 \times 10^{8}$ & $1.9 \times 10^{5}$ & $<3 \times 10^{3}$ & $<3 \times 10^{3}$ \\
\hline $14^{\mathrm{a}}$ & $2.5 \times 10^{4}$ & $2.7 \times 10^{9}$ & $8.6 \times 10^{4}$ & $9.7 \times 10^{3}$ & $<3 \times 10^{3}$ \\
\hline $15^{a}$ & $1.8 \times 10^{5}$ & $1.2 \times 10^{9}$ & $5.4 \times 10^{4}$ & $3.7 \times 10^{3}$ & $<3 \times 10^{3}$ \\
\hline $16^{\mathrm{a}}$ & $2.0 \times 10^{6}$ & $1.3 \times 10^{9}$ & $2.4 \times 10^{4}$ & $4.3 \times 10^{3}$ & $<3 \times 10^{3}$ \\
\hline 17 & $9.6 \times 10^{4}$ & $2.1 \times 10^{8}$ & $3.0 \times 10^{4}$ & $<3 \times 10^{3}$ & $3.8 \times 10^{7}$ \\
\hline $18^{\mathrm{a}}$ & $1.7 \times 10^{6}$ & $6.8 \times 10^{8}$ & $1.5 \times 10^{5}$ & $8.3 \times 10^{3}$ & $<3 \times 10^{3}$ \\
\hline 19 & $2.8 \times 10^{5}$ & $5.0 \times 10^{7}$ & $6.6 \times 10^{4}$ & $2.8 \times 10^{3}$ & $6.8 \times 10^{5}$ \\
\hline $20^{a}$ & $1.4 \times 10^{5}$ & $2.6 \times 10^{8}$ & $<3 \times 10^{3}$ & $6.9 \times 10^{3}$ & $<3 \times 10^{3}$ \\
\hline 21 & $<3 \times 10^{3}$ & $7.3 \times 10^{7}$ & $<3 \times 10^{3}$ & $6.3 \times 10^{3}$ & $<3 \times 10^{3}$ \\
\hline 22 & $<3 \times 10^{3}$ & $6.4 \times 10^{9}$ & $6.0 \times 10^{4}$ & $<3 \times 10^{3}$ & $4.2 \times 10^{6}$ \\
\hline $23^{a}$ & $<3 \times 10^{3}$ & $7.7 \times 10^{8}$ & $1.1 \times 10^{5}$ & $<3 \times 10^{3}$ & $<3 \times 10^{3}$ \\
\hline $24^{a}$ & $<3 \times 10^{3}$ & $7.5 \times 10^{7}$ & $1.2 \times 10^{5}$ & $<3 \times 10^{3}$ & $<3 \times 10^{3}$ \\
\hline 25 & $1.5 \times 10^{5}$ & $<3 \times 10^{3}$ & $<3 \times 10^{3}$ & $3.2 \times 10^{3}$ & $<3 \times 10^{3}$ \\
\hline
\end{tabular}

N.P., normal pituitary.

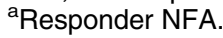

pasireotide did not significantly influence VEGF secretion (Fig. 1). In order to investigate whether SRIF and pasireotide influence VEGF secretion by interfering with the cAMP pathway, VEGF secretion was assessed in 5 'responder' NFA primary cultures treated for $8 \mathrm{~h}$ with or without $10^{-6} \mathrm{M}$ forskolin, and/ or $10^{-8} \mathrm{M}$ SRIF or pasireotide (Fig. 2). This NFA subgroup (including samples \#3, \#6, \#14, \#16, \#23) had a SSTR expression pattern and a mean number of SSTR1-5 mRNA molecules/ $\mu \mathrm{g}$ total RNA similar to those of the hole group of 'responders' (Table 5), indicating that these samples are representative of the responder NFA. Forskolin strongly induced VEGF secretion $(+110 \% ; P<0.01$ vs control). As described previously, treatment with both SRIF and pasireotide significantly reduced VEGF secretion $(-25$ and $-30 \% ; \quad P<0.05$ and $<0.01$ respectively) and completely abrogated forskolin-induced VEGF secretion.

\section{Effects of SRIF and of pasireotide on NFA cell viability}

In order to determine the effects of SRIF and of pasireotide on cell viability of dispersed NFA cells, we assessed cell number in NFA primary cultures after a $48 \mathrm{~h}$ treatment with SRIF or pasireotide.

In group A, cell viability was reduced by $15 \%$ after treatment with SRIF and by $16.5 \%$ after treatment with the multiligand SSTR agonist pasireotide $(P<0.05)$. On the other hand, in group B, treatment with SRIF or with pasireotide did not significantly influence cell viability (Fig. 3). In order to investigate whether SRIF and pasireotide influence cell viability by reducing VEGF secretion, cell viability was assessed in 5 'responder' NFA primary cultures treated for $48 \mathrm{~h}$ with or without $10 \mathrm{pg} / \mathrm{ml}$ VEGF and/or $10^{-8} \mathrm{M}$ SRIF or pasireotide (Fig. 4). This NFA sub-group (including samples \#5, \#13, \#15, \#18, \#24) had a SSTR expression pattern and a mean number of SSTR1-5 mRNA molecules/ $\mu$ g total RNA similar to those of the hole group of 'responders' (Table 5), indicating that these samples are representative of the responder NFA. VEGF significantly promoted NFA cell viability ( $+25 \% ; P<0.05$ vs control). As previously described, treatment with both SRIF and pasireotide significantly reduced cell viability $(-15$ and $-16 \%$ respectively; $P<0.05)$, and completely inhibited VEGF-induced increase in cell viability. 


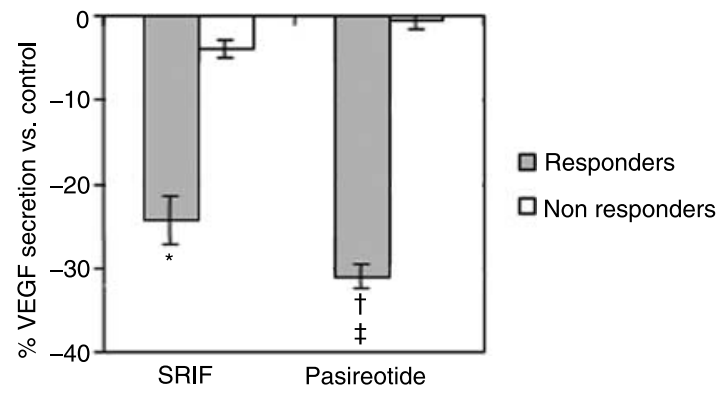

Figure 1 Effects of SRIF and pasireotide on VEGF secretion by NFA. Pituitary cells were incubated in 96-well plates for $8 \mathrm{~h}$ in culture medium supplemented with either SRIF or pasireotide at $10^{-8} \mathrm{M}$, and control cells were treated with vehicle solution. VEGF secretion by each primary culture was then measured by ELISA. As described in the Material and methods section, samples were divided according to VEGF secretion inhibition after treatment with SRIF in group A (responders, 13 samples, gray bars) and group B (non-responders, 12 samples, white bars). Data from NFA primary cultures were evaluated independently with eight replicates each, and were expressed as the mean \pm S.E.M. percent VEGF secretion inhibition versus untreated control cells. ${ }^{\star} P<0.05$ and ${ }^{\dagger} P<0.01$ vs untreated control cells; ${ }^{\ddagger} P<0.05$ vs SRIF-treated cells.

\section{Discussion}

This study confirms and extends previous findings concerning the antisecretory and antiproliferative potential of SSTR agonists in human NFA in vitro, and provides further insights on the possible mechanisms triggered by SSTRs in pituitary adenomas.

We have previously shown that SSTRs differently influence hormone secretion of a selected group of NFA in vitro (Zatelli et al. 2004). In the present study,

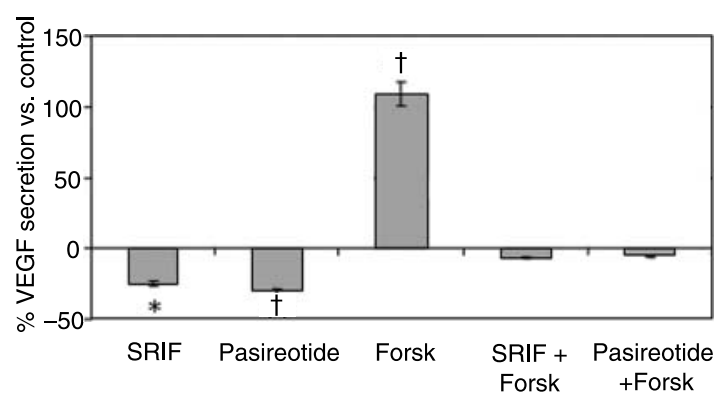

Figure 2 Effects of forskolin on VEGF secretion by NFA. Five 'responder' pituitary primary cultures were incubated in 96-well plates for $8 \mathrm{~h}$ in culture medium supplemented with either SRIF or pasireotide at $10^{-8} \mathrm{M}$, forskolin (Forsk) at $10^{-6} \mathrm{M}$ or both, and control cells were treated with vehicle solution. VEGF secretion by each primary culture was then measured by ELISA. Data from NFA primary cultures were evaluated independently with eight replicates each, and were expressed as the mean \pm S.E.M. percent VEGF secretion inhibition or induction vs untreated control cells. ${ }^{*} P<0.05$ and ${ }^{\dagger} P<0.01$ vs untreated control cells.

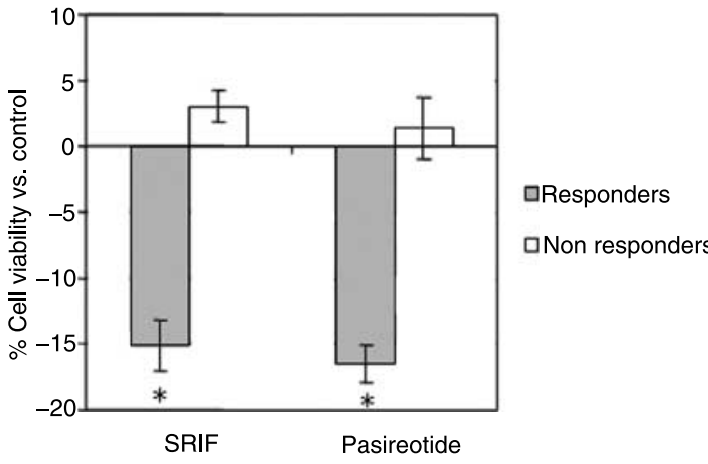

Figure 3 Effects of SRIF and pasireotide on NFA cell viability. Pituitary cells were incubated in 96-well plates for $48 \mathrm{~h}$ in culture medium supplemented with either SRIF or pasireotide at $10^{-}$ ${ }^{8} \mathrm{M}$, and control cells were treated with vehicle solution. Cell viability of each primary culture was measured as absorbance at $490 \mathrm{~nm}$. As described in the Material and methods section, samples were divided according to VEGF secretion inhibition after treatment with SRIF in group A (responders, 13 samples, gray bars) and group B (non-responders, 12 samples, white bars). Data from NFA primary cultures were evaluated independently with eight replicates each, and were expressed as the mean \pm S.E.M. percent cell viability inhibition vs. untreated control cells. ${ }^{\star} P<0.05$ vs untreated control cells.

we subdivided the NFA samples into two groups, according to the in vitro response to SRIF in terms of VEGF secretion reduction. This selection criterion allowed us to identify two distinct groups, since the group of 'responders' completely lacked SSTR5 expression. Interestingly, in this group a greater number of samples expressed SSTR1, as compared with the 'non-responder' group. On the other hand, no

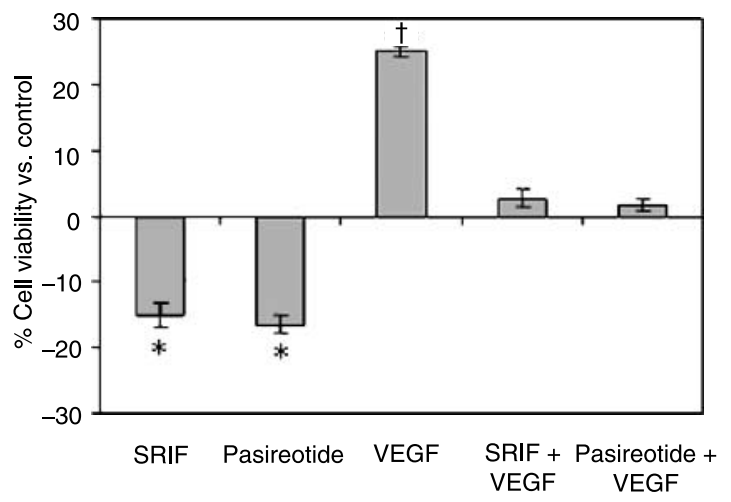

Figure 4 Effects of VEGF on NFA cell viability. Five 'responder' pituitary primary cultures were incubated in 96-well plates for $48 \mathrm{~h}$ in culture medium supplemented with either SRIF or pasireotide at $10^{-8} \mathrm{M}, 10 \mathrm{pg} / \mathrm{ml} \mathrm{VEGF} \mathrm{or} \mathrm{both,} \mathrm{and} \mathrm{control} \mathrm{cells}$ were treated with vehicle solution. Cell viability of each primary culture was measured as absorbance at $490 \mathrm{~nm}$. Data from NFA primary cultures were evaluated independently with eight replicates each, and were expressed as the mean \pm S.E.M. percent cell viability inhibition or induction vs untreated control cells. ${ }^{*} P<0.05$ and ${ }^{\dagger} P<0.01$ vs untreated control cells. 
further difference was found between the two groups in terms of clinical characteristics or tumor volume. Our results show that the 'responder' group responds to SRIF and to pasireotide in terms of VEGF secretion inhibition, indicating that functionally active SSTRs are indeed expressed by these primary cultures. This evidence indicates that the signaling pathway downstream from SSTRs regulating the secretory processes is intact in these samples. This hypothesis is further supported by the evidence that SRIF and pasireotide can completely abrogate the effects of forskolin, a well known adenylate cyclase activator, on VEGF secretion. This evidence demonstrates that in NFA primary cultures SSTR agonists are capable of activating the respective receptors, which, in turn, can trigger intracellular pathways. In our hands, pasireotide was more effective than SRIF in reducing VEGF secretion in the 'responder' group. The greater potency of this compound might be due to high affinity binding to several SSTR subtypes (Bruns et al. 2002, Lamberts et al. 2002). However, pasireotide has a fiveand a four-fold lower affinity to SSTR1 and SSTR2 respectively, than SRIF. Therefore, the greater potency might be ascribed to the prolonged half-life of the compound and to the reduced induction of SSTR desensitization (Bruns et al. 2002). Pasireotide has a greater affinity for SSTR5 as compared to SRIF, but the 'responder' group does not express such receptor. Moreover, in the 'responder' group, the reduction in VEGF secretion is mirrored by a nearly parallel reduction in cell viability induced by treatment with SRIF or pasireotide. These results suggest that, at least in part, the antiproliferative effects of SRIF analogs might be mediated by a reduced VEGF secretion. This hypothesis is further strengthened by the evidence that SRIF and pasireotide completely abrogated the promoting effects of VEGF on cell viability.

In the 'non-responder' group, SRIF and pasireotide did not influence both VEGF secretion and cell viability. This evidence might suggest that these NFA display functionally inactive SSTRs, or that the signaling pathways downstream from SSTRs are somehow disrupted. The lack of SSTR5 expression in all NFA samples belonging to the 'responder' group and the presence of this receptor in most of the 'nonresponder' group also suggests that SSTR5 might interact with the other SSTRs, hampering receptor activation, inhibiting intracellular signaling or counteracting the effects of other SSTRs activation. This latter hypothesis is in line with our previous data showing that a SSTR5-selective agonist promotes cell viability in a selected group of NFA expressing SSTR5 (Zatelli et al. 2004). These data would indicate a stimulatory role for SSTR5 in NFA cell proliferation, suggesting that the use of compounds selectively interacting with SSTR5 in NFA medical therapy might be counterproductive. In addition, this effect might account for the lack of volume reduction (Colao et al. 2000, Andersen et al. 2001) or the increase in tumor volume (Gasperi et al. 1993) observed in NFA patients treated with octreotide or lanreotide, which mainly interacts with SSTR2 and SSTR5. However, this does not seem to be a general mechanism in pituitary adenomas, because previous evidence from somatotroph and corticotroph pituitary tumors suggests that the additional activation of SSTR5 might be responsible for the enhanced efficacy of SRIF analogs in reducing both secretion and cell proliferation (Shimon et al. 1997, Hofland et al. 2005). Moreover, some of the 'non-responder' NFA also lacked SSTR5 expression, suggesting that in these tumors pasireotide failure in reducing VEGF secretion should be ascribed to other mechanisms or to different SSTRs. It should be noted, indeed, that these NFA samples also lacked SSTR3 expression, which was nearly two-fold greater in 'responders' as compared with 'non-responders' NFA. It has been previously demonstrated that SSTR3 activation induces apoptosis through a p53dependent mechanism (Sharma et al. 1996). We can therefore hypothesize that SRIF and pasireotide might exert their inhibitory effects also by interacting with SSTR3, which is more expressed in 'responder' tumors. Similarly, SSTR1 activation has been demonstrated to effectively reduce cell viability not only in NFA (Zatelli et al. 2004), but also in GH/PRLsecreting pituitary adenomas (Zatelli et al. 2003a). The data presented here are in line with an antiproliferative effect of SSTR1-interacting drugs in pituitary adenomas, since, nearly $80 \%$ of 'responder' NFA express SSTR1. It has been demonstrated that SSTR1 activation results in decreased secretory activity and reduced cell viability also in medullary thyroid carcinoma (Zatelli et al. 2006a,b), suggesting that SSTR1 agonists may be effective on a wide range of endocrine cells. Indeed, almost all human tumors express SSTR1 mRNA (Patel 1997), suggesting that compounds also targeting SSTR1, such as pasireotide, might represent a good tool for the control of neoplastic growth. Moreover, an immunohistochemical study demonstrated that SSTR1 is one of the most expressed SSTR subtypes in NFA (Pawlikowski et al. 2003). Therefore, stable SRIF analogs binding with high affinity to SSTR1, whether selectively or together with other SSTR subtypes, may indeed open a new frontier in the treatment of NFA. 
The SSTR2 subtype has been implicated in transducing the antiproliferative effects of SRIF in many animal and human models (Zatelli et al. 2001, 2002, 2005, 2006a,b, Guillermet-Guibert et al. 2005). We previously reported that, in a selected group of NFA, SSTR2 selective activation was ineffective in influencing cell viability in vitro (Zatelli et al. 2004). In the present report both the 'responder' and the 'nonresponder' group equally expressed SSTR2, further supporting the hypothesis that the expression of multiple SSTR subtypes might profoundly influence the final effect of simultaneous receptor activation, as in the presence of a multireceptor ligand such as pasireotide. A similar mechanism might be supposed for SSTR3, which is equally expressed both in the 'responder' and the 'non-responder' groups, and has previously been demonstrated to promote apoptosis upon activation (Sharma et al. 1996).

VEGF has been implicated in the angiogenetic processes in pituitary adenomas, even if the role of increased vascularity in pituitary tumors is still controversial. Some authors indeed report increased angiogenesis in pituitary adenomas (Weiner et al. 1995), while others observe a reduced intratumoral vessel number (Turner et al. 2000). VEGF mRNA expression has been demonstrated to be increased in NFA, where it associates with the expression of pituitary tumor transforming gene (PTTG). It has been demonstrated that PTTG transforms cells in vitro and is tumorigenic in vivo, being also capable of inducing VEGF expression (McCabe et al. 2002). These data suggest that autocrine VEGF secretion might contribute to pituitary adenoma cell proliferation and/or transformation. Our data are in agreement with previous evidence showing that VEGF and its receptor, VEGF-R1, are widely expressed in NFA (McCabe et al. 2002), also providing the basis of a possible autocrine loop. In addition, our results support the hypothesis that SRIF analogs might exert their antiproliferative effects by reducing VEGF secretion, consequently hampering VEGF effects. Indeed, treatment with SRIF and pasireotide completely abrogates the growth-promoting effects VEGF on NFA primary cultures. In addition, it has been previously reported that octreotide reduces blood vessel growth (Woltering et al. 1991) and inhibits proliferation of human umbilical vein endothelial cells (Danesi et al. 1997). Our data also indicate that VEGF might promote pituitary proliferation both indirectly, by stimulating angiogenesis, and directly by promoting cell viability.

In conclusion, our results demonstrate that, in vitro, SRIF and pasireotide inhibit both VEGF secretion and cell viability in a subset of NFA. Our data are consistent with a greater effect for the multiligand SRIF analog pasireotide and suggest that the antiproliferative effects of SRIF agonists on NFA primary cultures might be mediated, at least in part, by VEGF secretion inhibition, with a consequent reduction in the autocrine growth factor loop.

\section{Acknowledgements}

This work was supported by grants from the Italian Ministry of University and Scientific and Technological Research (MIUR 2005060839-004), Fondazione Cassa di Risparmio di Ferrara, the Associazione Ferrarese dell'Ipertensione Arteriosa, and the Associazione Terapie Neurochirurgiche Avanzate (ATENA). The Authors would like to thank Dr Franco Mainini (Novartis Farma, Italy) for his continuous support and for critical evaluation of the manuscript. The authors declare that there is no conflict of interest that would prejudice the impartiality of this scientific work.

\section{References}

Adams RL, Adams IP, Lindow SW \& Atkin SL 2004 Inhibition of endothelial proliferation by the somatostatin analogue pasireotide. Clinical Endocrinology 61 431-436.

Andersen M, Bjerre P, Schroder HD, Edal A, HoilundCarlsen PF, Pedersen PH \& Hagen C 2001 In vivo secretory potential and the effect of combination therapy with octreotide and cabergoline in patients with clinically non-functioning pituitary adenomas. Clinical Endocrinology 54 23-30.

Bruns C, Lewis I, Briner U, Meno-Tetang G \& Weckbecker G 2002 SOM230: a novel somatostatin peptidomimetic with broad somatotropin release inhibiting factor (SRIF) receptor binding and a unique antisecretory profile. European Journal of Endocrinology 146 707-716.

Carrere N, Vernejoul F, Souque A, Asnacios A, Vaysse N, Pradayrol L, Susini C, Buscail L \& Cordelier P 2005 Characterization of the bystander effect of somatostatin receptor sst 2 after in vivo gene transfer into human pancreatic cancer cells. Human Gene Therapy 16 1175-1193.

Chelly J, Concordet JP, Kaplan JC \& Kahn A 1989 Illegitimate transcription: transcription of any gene in any cell type. PNAS 86 2617-2621.

Colao A, Di Sarno A, Marzullo P, Di Somma C, Cerbone G, Landi ML, Faggiano A, Merola B \& Lombardi G 2000 New medical approaches in pituitary adenomas. Hormone Research 53 76-87.

Danesi R, Agen C, Benelli U, Di Paolo A, Nardini D, Bocci G, Basolo F, Campagni A \& Del Tacca M 1997 Inhibition of 
experimental angiogenesis by the somatostatin analogue octreotide acetate (SMS 201-995). Clinical Cancer Research 3 265-272.

Danila D, Sleiman Haidar JN, Zhang X, Katznelson L, Culler MD \& Klibanski A 2001 Somatostatin receptor specific analogs: effects on cell proliferation and growth hormone secretion in human somatotroph tumors. Journal of Clinical Endocrinology and Metabolism 86 2976-2981.

Ferrara N 2001 Role of vascular endothelial growth factor in regulation of physiological angiogenesis. American Journal of Physiology. Cell Physiology $\mathbf{2 8 0}$ C1358-C1366.

Gasperi M, Petrini L, Pilosu R, Nardi M, Marcello A, Mastio F, Bartalena L \& Martino E 1993 Octreotide treatment does not affect the size of most non-functioning pituitary adenomas. Journal of Endocrinological Investigation 16 541-543.

Guillermet-Guibert J, Lahlou H, Cordelier P, Bousquet C, Pyronnet S \& Susini C 2005 Physiology of somatostatin receptors. Journal of Endocrinological Investigation 28 5-9.

Hofland LJ, van der Hoek J, Feelders R, van der Lely AJ, de Herder W \& Lamberts SW 2005 Pre-clinical and clinical experiences with novel somatostatin ligands: advantages, disadvantages and new prospects. Journal of Endocrinological Investigation 28 36-42.

Hubina E, Nanzer AM, Hanson MR, Ciccarelli E, Losa M, Gaia D, Papotti M, Terreni MR, Khalaf S, Jordan S et al. 2006 Somatostatin analogues stimulate p27 expression and inhibit the MAP kinase pathway in pituitary tumours. European Journal of Endocrinology 155 371-379.

Itakura J, Ishiwata T, Friess H, Fujii H, Matsumoto Y, Buchler MW \& Korc M 1997 Enhanced expression of vascular endothelial growth factor in human pancreatic cancer correlates with local disease progression. Clinical Cancer Research 3 1309-1316.

Komorowski J, Jankewicz J \& Stepien H 2000 Vascular endothelial growth factor (VEGF), basic fibroblast growth factor (bFGF) and soluble interleukin-2 receptor (sIL-2R) concentrations in peripheral blood as markers of pituitary tumours. Cytobios 101 151-159.

Korbonits M, Bustin SA, Kojima M, Jordan S, Adams EF, Lowe DG, Kangawa K \& Grossman AB 2001 The expression of the growth hormone secretagogue receptor ligand ghrelin in normal and abnormal human pituitary and other neuroendocrine tumors. Journal of Clinical Endocrinology and Metabolism 86 881-887.

Lamberts SW, van der Lely AJ \& Hofland LJ 2002 New somatostatin analogs: will they fulfil old promises? European Journal of Endocrinology 146 701-705.

McCabe CJ, Boelaert K, Tannahill LA, Heaney AP, Stratford AL, Khaira JS, Hussain S, Sheppard MC, Franklyn JA \& Gittoes NJ 2002 Vascular endothelial growth factor, its receptor $\mathrm{KDR} / \mathrm{Flk}-1$, and pituitary tumor transforming gene in pituitary tumors. Journal of Clinical Endocrinology and Metabolism 87 4238-4244.

Patel YC 1997 Molecular pharmacology of somatostatin receptor subtypes. Journal of Endocrinological Investigation 20 348-367.

Pawlikowski M, Pisarek H, Kunert-Radek J \& Radek A 2003 Immunihistochemical detection of somatostatin receptor subtypes in 'Clinically Nonfunctioning' pituitary adenomas. Endocrine Pathology 14 231-238.

Schmid HA \& Schoeffter P 2004 Functional activity of the multiligand analog SOM230 at human recombinant somatostatin receptor subtypes supports its usefulness in neuroendocrine tumors. Neuroendocrinology 80 47-50.

Seo Y, Baba H, Fukuda T, Takashima M \& Sugimachi K 2000 High expression of vascular endothelial growth factor is associated with liver metastasis and a poor prognosis for patients with ductal pancreatic adenocarcinoma. Cancer 88 2239-2245.

Sharma K, Patel YC \& Srikant CB 1996 Subtype-selective induction of wild-type p53 and apoptosis, but not cell cycle arrest, by human somatostatin receptor 3. Molecular Endocrinology 10 1688-1696.

Shimon I, Yan X, Taylor JE, Weiss MH, Culler MD \& Melmed S 1997 Somatostatin receptor (SSTR) subtype-selective analogues differentially suppress in vitro growth hormone and prolactin in human pituitary adenomas. Novel potential therapy for functional pituitary tumors. Journal of Clinical Investigation 100 2386-2392.

Turner HE, Nagy Z, Gatter KC, Esiri MM, Harris AL \& Wass JA 2000 Angiogenesis in pituitary adenomas and the normal pituitary gland. Journal of Clinical Endocrinology and Metabolism 85 1159-1162.

Vidal S, Oliveira MC, Kovacs K, Scheithauer BW \& Lloyd R 2000 Immunolocalization of vascular endothelial growth factor in the GH3 cell line. Cell and Tissue Research 300 83-88.

Weckbecker G, Briner U, Lewis I \& Bruns C 2002 SOM230: a new somatostatin peptidomimetic with potent inhibitory effects on the growth hormone/insulin-like growth factorI axis in rats, primates, and dogs. Endocrinology 143 4123-4130.

Weiner RL, Elias KA \& Monnet F 1995 Prolactin. In Basic and Clinical Correlates, pp 641-653. Eds RM Macleod, MO Thorner \& U Scapagnini. Padova: Liviana Press.

Woltering EA, Barrie R, O'Dorisio TM, Arce D, Ure T, Cramer A, Holmes D, Robertson J \& Fassler J 1991 Somatostatin analogues inhibit angiogenesis in the chick chorioallantoic membrane. Journal of Surgical Research 50 245-251.

Yamada S \& Takada K 2003 Angiogenesis in pituitary adenomas. Microscopy Research and Technique 60 236-243. 
Zatelli MC, Tagliati F, Taylor JE, Rossi R, Culler MD \& degli Uberti EC 2001 Somatostatin receptor subtypes 2 and 5 differentially affect proliferation in vitro of the human medullary thyroid carcinoma cell line TT. Journal of Clinical Endocrinology and Metabolism 86 2161-2169.

Zatelli MC, Tagliati F, Piccin D, Taylor JE, Culler MD, Bondanelli M \& degli Uberti EC 2002 Somatostatin receptor subtype 1 selective activation reduces cell growth and calcitonin secretion in a human medullary thyroid carcinoma cell line. Biochemical and Biophysical Research Communications 297 821-827.

Zatelli MC, Piccin D, Tagliati F, Ambrosio MR, Margutti A, Padovani R, Scanarini M, Culler MD \& degli Uberti EC $2003 a$ Somatostatin receptor subtype 1 selective activation in human growth hormone- and prolactin-secreting pituitary adenomas: effects on cell viability, growth hormone and prolactin secretion. Journal of Clinical Endocrinology and Metabolism 88 2797-2802.

Zatelli MC, Piccin D, Bondanelli M, Tagliati F, De Carlo E, Culler MD \& degli Uberti EC 2003 b An in vivo Octreoscan-negative adrenal pheochromocytoma expresses somatostatin receptors and responds to somatostatin analogs treatment in vitro. Hormone and Metabolic Research 35 349-354.
Zatelli MC, Piccin D, Bottoni A, Ambrosio MR, Margutti A, Padovani R, Scanarini M, Taylor JE, Culler MD, Cavazzini L et al. 2004 Evidence for differential effects of selective somatostatin receptor subtype agonists on alphasubunit and chromogranin a secretion and on cell viability in human nonfunctioning pituitary adenomas in vitro. Journal of Clinical Endocrinology and Metabolism 89 5181-5188.

Zatelli MC, Piccin D, Tagliati F, Bottoni A, Luchin A \& degli Uberti EC 2005 SHP-1 restrains cell proliferation in medullary thyroid carcinoma. Endocrinology 146 2692-2698.

Zatelli MC, Piccin D, Tagliati F, Bottoni A, Luchin A, Vignali C, Margutti A, Bondanelli M, Pansini GC, Pelizzo MR et al. $2006 a$ Selective activation of somatostatin receptor subtypes differentially modulates secretion and viability in human medullary thyroid carcinoma primary cultures: potential clinical perspectives. Journal of Clinical Endocrinology and Metabolism 91 2218-2224.

Zatelli MC, Piccin D, Ambrosio MR, Bondanelli M \& degli Uberti EC $2006 b$ Antiproliferative effects of somatostatin analogs in pituitary adenomas. Pituitary 9 27-34. 